\title{
DISCURSOS Y PRÁCTICAS DESPATOLOGIZANTES, APORTES DESDE LA NARRATIVA: LA FÁBRICA DE LA LOCURA
}

Gastón Pérez $^{1}$

\section{Introducción}

Escribir este trabajo, ha sido sin lugar a dudas, de las tareas más difíciles a nivel profesional/académico en las que me he embarcado. Lejos de versar sobre mundos externos, lejanos, no puedo separar lo que voy a decir durante las siguientes páginas de mi mundo interno. Distanciado de supuestas pretensiones de objetividad, este es un artículo confesa, expresa y orgullosamente subjetivo. Se basa en la intervención y el vínculo con una persona mayor con diagnóstico de demencia en el Centro de Recuperación estatal donde desempeño mi actividad profesional como trabajador social, desarrollada entre mediados de 2016 y fines de 2017.

El mismo, ubicado en el barrio Prado de la ciudad de Montevideo, tiene como población objetivo, personas en situación de calle ${ }^{2}$ con alta médica de centros de salud, que no cuenten con solución habitacional para cursar una recuperación sanitaria (ejemplos frecuentes: fractura de cadera, úlcera, neumonía, etc.). Situación económica y falta de redes de sostén (nivel vincular), consisten dos problemáticas centrales desde las que trabajamos. Diseñado desde la lógica médica-sanitaria, con un importante equipo de enfermería, y una cooperativa de acompañantes/cuidadoras por turno, el área psicosocial se reduce a dos técnicos, psicóloga y trabajador/a social, en la mañana y en la tarde.

La explicaciones, y las definiciones de realidad, son capturadas mayormente desde la lógica médica, (re)producidas desde el paradigma positivista. Correrse a la hora del abordaje de estas explicaciones, conlleva diversas reacciones desde la mencionada cosmovisión, muchas veces en el plano de la locura, extravagancia o pérdida de tiempo. Claro ejemplo de esto, lo experimentamos en el trabajo con personas con diagnóstico de demencia, las cuales son reducidas a cerebros con múltiples déficits cognitivos en

\footnotetext{
${ }^{1}$ Universidad de la República (UdelaR), Uruguay.

2 Categoría generalizada por parte de los técnicos del área psicosocial, para referirse a las personas que no tienen acceso tanto a la vivienda como a servicios básicos para la reproducción social.
} 
acuerdo con el manual psiquiátrico DSM IV (American Psychiatric Association (1994) ${ }^{3}$. Este artículo se construye desde el lugar contrario, desde la implicación, el conocimiento situado (Martínez-Guzmán y Montenegro, 2010), desde los relatos de los involucrados y las significaciones personales.

Escribir desde la emoción, más que un acto poético, es un acto político. Ello es algo que aprendí en el curso de la intervención con Alberto ${ }^{4}$, usuario del Centro de Recuperación durante un año y unos pocos meses.

Desde el saber médico-biologicista, el diagnóstico no admitía demasiado margen de duda: demencia tipo Alzheimer, con afectación en áreas cognitivas de la memoria y las funciones ejecutivas (planificación, toma de decisiones). Actualmente incluida dentro de los trastornos neurocognitivos (TNC) en el manual DSM V:

Los TNC son aquellos en los que la disfunción cognitiva no ha estado presente desde el nacimiento o la infancia temprana y, por tanto, representa un declive desde un nivel de funcionamiento adquirido previamente (American Psychiatric Association, 2013: 591)

Los cuatro criterios diagnósticos establecidos en el DSM V (American Psychiatric Association, 2013) para los TNC parecían explicar perfectamente la situación de Alberto: declive cognitivo, pérdida de autonomía, déficits no asociados exclusivamente en contexto de delirium ni por otro trastorno mental (ej. esquizofrenia).

La enfermedad de Alzheimer, tanto en la fase TNC leve como en la fase TNC mayor, implicaría un declive de la memoria y del aprendizaje en donde el diagnóstico cobra efectos apocalípticos: "El TNC mayor o leve debido a la enfermedad de Alzheimer progresa gradualmente, en ocasiones con breves mesetas, hacia la demencia grave y la muerte” (American Psychiatric Association, 2013: 612)

Definir a una persona en términos de demencia, implica entonces definirla como declive, comienzo del fin. Producida en clave de ley universal, las producciones culturales, si bien no se desconocen, son cooptadas por esta normatividad hegemónica:

La detección de un TNC puede ser más difícil en los entornos culturales y socioeconómicos en los que la pérdida de memoria se considera normal a edades avanzadas, en los que los ancianos tienen menos exigencias cognitivas en la vida diaria y en los que los niveles educativos muy bajos suponen un mayor reto para realizar una evaluación cognitiva objetiva (American Psychiatric Association, 2013: 613)

\footnotetext{
3 “Tiene el cerebro quemado”, “le falta medio cerebro”, son parte del repertorio del equipo técnico en clave biologicista.

${ }^{4}$ Por razones de confidencialidad, se ha modificado el nombre de pila para proteger su identidad.
} 
Una normatividad cultural que elabora la diferencia desde la desviación. Lo diferente, más que cuestionar el saber, entorpece y dificulta el camino de la verdad/objetividad. Sin embargo, a la hora de explicitar una etiología, esta verdad biológica-objetiva-natural se desvanece en relativismos, “posible”, “probable”, “pueden tener valor diagnóstico” (American Psychiatric Association, 2013), en la confianza a futuro que lo que no está del todo validado hoy, será demostrado en los años venideros. ¿Y qué hacemos con tanta ciencia?

Este artículo consiste en una sistematización y reflexión sobre la intervención con Alberto. Desarrollaré que la misma sólo pudo ser posible cuando se lo dejó de ver como un cerebro con déficits cognitivos, y se lo pensó como una persona sociohistórica, con sus fantasmas inseparables de sus contextos culturales, pensada por fuera de la lógica totalizante y estigmatizante de la locura.

Cuestionar la categoría de enfermedad mental, pensar las lógicas del podersaber, problematizar la institución, el lenguaje y la narrativa como creadoras de realidad. Realidades que se abren cuando se cambian los lentes con los que se interpreta, herramientas para construir nuevas narrativas, nuevas formas de intervenir, de vincularse y de entender/entenderse. Sin desconocer el sufrimiento, y las dificultades para funcionar socialmente en el contexto de normas sociales e institucionales, me pregunto: ¿qué utilidad tiene la lógica de la patologización? ¿A quién o a qué sirve?

Por fuera de pseudo hallazgos de moda asociados a lógicas de mercado que imponen el paradigma de lo novedoso como motor de consumo, la salud/enfermedad mental más que una entidad en sí misma, no deja de resonarme a viejos dilemas y aprendizajes antropológicos sobre cómo pensar la diferencia.

\section{Problematizando los discursos/prácticas: la herencia positivista}

Para analizar una práctica de intervención que logró sus condiciones de posibilidad en el distanciamiento de los supuestos positivistas, rescato los aportes de Hüning y Guareschi (2005), sobre la problematización de las prácticas psi articuladas con el pensamiento foucaultiano. Ello genera una ruptura con las formas clásicas de concebir la intervención en su complejidad (no sólo política, epistemológica, sino también en su multiplicidad de formas o momentos, como el momento diagnóstico). 
Entendiendo a la producción de conocimiento como discursos que generan, permiten y validan formas de ser, la teoría y la práctica dejan de ser actividades disociadas.

Desde este planteo, la ciencia pierde carácter sagrado en la pretensión omnipresente de demostrar o explicar lo real. Pensada como "regímenes de verdad", se validan formas de ser y de estar en el mundo (Hüning y Guareschi, 2005). Esta construcción de subjetividad se enmarca en la noción de dispositivo de Foucault (1984), como red de elementos heterogéneos, discursos, instituciones, medidas administrativas, leyes, enunciados científicos, elementos de lo dicho como de lo no-dicho, que permiten, validan o por el contrario ocultan prácticas, a partir de una función estratégica dominante.

Los dispositivos desde donde se define la normalidad/anormalidad -como juegos de poder-saber y estrategias de relaciones de fuerza que soportan y son soportadas por tipos de saber (Foucault, 1984)- lejos de ser producciones científicas neutras, reflejos de la naturaleza, consisten en conjuntos más o menos coordinados de relaciones que generan discursos y prácticas.

Ahora bien, aún reconociendo la avanzada de posturas epistemológicas críticas y desnaturalizadoras, el positivismo se configura como parte central de nuestra herencia, filtrándose por los recovecos más insospechados de nuestros discursos/prácticas. Reconstruyendo las raíces de la psicología, esta herencia positivista se observa en el paradigma de la “ciencia de la conducta” (Hüning y Guareschi, 2005), el cual se lanza a la revelación de la interioridad del sujeto, suponiendo la pre-existencia de ésta.

La noción de sujeto universal como unidad a-social, escindido de los contextos desde donde se lo produce como tal, no es azarosa, sino teórica-política y una clara herencia en nuestros discursos/prácticas y relaciones de poder. La ciencia, y por ende los/as representantes de la misma, amparados en regímenes de verdad, tenemos la potestad de versar sobre el mundo, ocupando lugares estratégicos que producen modos de subjetividad, esquemas válidos de ser, estar, pensar y sentir, demarcando las fronteras entre lo normal/anormal, entre lo sano/patológico.

La noción foucaultiana de realidad, pensada no como algo dado sino en constante (re)producción, contrasta con la búsqueda obsesiva de ordenamiento y eficacia de la modernidad, desde la cual se entiende lo real como algo dado y asequible a la racionalidad humana. La ilusión de orden y pureza, en una realidad dada y controlable, genera la necesidad de encargarse de su contracara, el desorden y la 
suciedad como forma de suprimir las ambivalencias y clasificar las contingencias (Hüning y Guareschi, 2005). Ya sea la supuesta cura o el aislamiento, quienes aparecen como las corporificaciones de la suciedad, sufrirán en carne propia el impulso racionalizador de la modernidad.

La patologización, y la etiqueta de enfermo mental, responden a la noción de un sujeto universal, con sus estados de desarrollo y modos de existencia pre-determinados. Ésta se operativiza a través del diagnóstico, el cual implica una definición de realidad, desde un lugar de poder amprado en un régimen de verdad. Diagnosticar entonces se convierte en una forma de intervenir, que lejos de la neutralidad, implica la producción de sujetos y de modos de existencia.

Centrar la preocupación en discursos/diagnósticos/prácticas desestigmatizantes y despatologizantes, las cuales promuevan la producción de alteridades, conlleva arrojarse al caos de la falta de respuestas inmediatas, a la incertidumbre y a la emoción de lo nuevo, a la renuncia de las causalidades y las explicaciones pre-diseñadas. Si queremos producir prácticas que escapen del lugar común de la patologización, es necesario generar teoría que problematice los esquemas positivistas naturalizados, cuestionando más que la verdad o falsedad del saber, sus funciones de poder-saber (Foucault, 1990 en Hüning y Guareschi, 2005).

Dicha producción, en cuanto crítica del proceso del poder, se alinea a los postulados de la Gerontología Crítica. De esta forma, la vejez y el envejecimiento no tienen nada de dado, o natural, sino que consisten en construcciones que validan, o por el contrario invalidan, formas de ser y de estar en el mundo. Distanciarse de un sujeto universal, y de formas cristalizadas de entender la vejez y a los/as viejos/as, implica la necesaria crítica de los supuestos positivistas del conocimiento y la ciencia (Bengston, 1997).

Para lograr una problematización del discurso/práctica, que promueva la búsqueda de narrativas despatologizantes, es preciso cuestionar la propia intervención realizada desde la asimetría del poder. En el caso de la práctica a analizar en este artículo, entre quien ingresa como usuario del Centro de Recuperación, y quien representa a los regímenes de verdad, donde la institución racionaliza como forma de aprehender lo caótico: es un demente, una situación de calle, una desvinculación familiar. 


\section{Lo loco de la enfermedad mental}

Uno de los correlatos más claros y vigentes de la herencia positivista en la gerontología social, se encuentra en las teorías del declive, formuladas a mediados del S. XX. Éstas se enmarcan en la primera generación de teorías, las cuales centran su foco en la adaptación/inadaptación de la persona mayor a un declive como ley natural, y en la capacidad de interacción de la persona con su medio social (Díaz-Tendero, 2011).

Las teorías del declive consideran al envejecimiento como una progresiva separación de la sociedad de orden natural y universal. El fundamento es predominantemente biologicista, en tanto un cuerpo que comienza a declinar es acompasado por un cerebro también en declive. Esta teoría lejos de estar descartada, se alinea con el paradigma racionalizador-biologicista, el cual no es patrimonio exclusivo de la medicina y la psiquiatría ${ }^{5}$.

El declive produce entonces a la vejez, a la persona, desde un cuerpo orgánico en constante y progresivo deterioro. En este marco, la demencia queda colocada como una suerte (¿desgracia?) de profecía auto cumplida del natural desenlace, la crónica de una muerte anunciada de un proceso gradual de deterioro. ¿Lo normal es entonces ser un viejo demente? ¿Lo loco es envejecer?

Esta patologización de la vejez no es una cuestión exclusivamente médica, ni debe ser un tabú por parte de quienes producimos desde lugares de saber, sino que es parte central de nuestros discursos/prácticas. Pensemos por ejemplo en la hipótesis psicologicista de Goldfarb (2004), de entender la demencia como producto de duelos no elaborados, que no logran colocar nuevas investiduras sobre otros objetos, añadido al duelo intrínseco a la vejez relacionado a la conciencia de finitud.

Ahora bien, dicha hipótesis puede ser tomada por un lado como única explicación etimológica de las demencias, lo cual implicaría una pérdida en el potencial explicativo y explorador de la misma, bajo la pretensión de ley general de un sujeto universal y a-temporal, el cual cargaría con el a priori de la elaboración de pérdidas debido a una supuesta-real conciencia de finitud.

Como señalan Berriel y Pérez (2007), toda propuesta con pretensión

\footnotetext{
${ }^{5}$ Una postura crítica, implica poder incluir las tensiones y contradicciones desde las cuales pensamos/hablamos/intervenimos. Realizar una suerte de demonización de lo médico, es un alivio para la producción de conocimiento desde lo social, porque genera un enemigo en común, y casi sin quererlo, queda la producción propia desde un lugar aséptico.
} 
hegemónica, pierde potencial comprensivo para convertirse en un dogma. Lo que nos lleva a otra interpretación posible, la de la autora. Explica Goldfarb en el prólogo de Psicoterapia y Alzheimer (Berriel y Pérez, 2007), que supone un error adjudicar los procesos demenciales exclusivamente a procesos psicosociales. Destaco por lo tanto la importancia de no competir con el positivismo reproduciendo la misma lógica de pensamiento, en donde se reemplacen leyes universales naturales por leyes universales de la mente y lo social.

Siguiendo con la mencionada autora, el término demencia encuentra su raíz etimológica del latín, de-mentis, lo que se puede traducir como perder la mente. La demencia aparece como una de las tantas manifestaciones de la locura, en tanto conllevaría una pérdida de la razón. Este alejamiento de lo real, se refleja en la producción de la psiquiatría clásica en Krapelin a principios del siglo XX, al entender a las demencias dentro de las "locuras involutivas", interpretando las alteraciones de conducta en el marco de desórdenes biológicos (Berriel y Pérez, 2007).

Si bien es posible extenderse en definiciones de locura, ya sea en discusiones sobre estructuras psíquicas o tal o cual trastorno reciclado a través de los años, opto en este trabajo por definirla quizás de la forma más simple y más potente que pueda pensar, me refiero a definirla por lo que no es.

Simplemente, la locura no es la normalidad. Lo cual guía necesariamente a la siguiente pregunta: ¿qué es lo normal?

Señala Szasz (2001), en la medida que las ciencias de la conducta versan sobre lo que las personas hacen/no hacen, piensan/no piensan, no pueden disociarse de un contexto de valores, y por ende de juicios morales. La pretensión de neutralidad positivista, no hace otra cosa que oscurecer el proceso de construcción de subjetividad desde lugares de poder-saber. Deconstruir cómo y desde dónde se producen estos discursos, implica deconstruir lo que se entiende por normalidad. Aquí el asunto es de orden epistemológico, y reside en dónde se ponga énfasis: ya sea en la naturaleza de la normalidad/desviación, o en la construcción de la normatividad que produce nociones de naturaleza.

La conducta humana no sucede en el vacío, sino que se encuentra regida por principios humanos (Szasz, 2001), principios éticos que separan el bien del mal, lo 
correcto de lo incorrecto. De esta forma, toda conducta humana ${ }^{6}$ es una conducta moral, en la medida que está atravesada por una ética triunfante, lleva implícita un deber ser, una significación, una normatividad. En palabras de Szasz (2001, 12): “afirmar que una persona está mentalmente enferma, implica formular un juicio moral sobre ella”. La persona capturada en la categoría demente sufre entonces una amputación en términos morales, vivencia lo rápido que puede ser convertirse en un loco al perder la mente.

Estos perdedores morales son privados de una de las más hermosas libertades de las que gozamos los normales: la capacidad de que sucedan cosas increíbles, la belleza de la casualidad menos pensada, hacer un hoyo en 1 sin saber jugar al golf. El estigma de la locura es tal, que cualquier relato que no parezca hiper-adaptado, cae automáticamente en el descrédito. De esta forma, le exigimos a los locos, discursos caricaturescos sobre lo real, donde la fantasía y la magia, son producto de visiones enfermas de lo real.

Esta privación, en donde se borra toda sorpresa y mística, es uno de los mayores, y más silenciosos ejercicios de violencia que se perpetran sobre la locura.

Recuerdo una anécdota que ejemplifica esto en forma sintética. En una reunión de equipo del Centro de Recuperación, conversando sobre una persona con diagnóstico de demencia, una compañera trae como ilustración de su deterioro y su estado “confusional”, que el señor había solicitado días atrás al equipo de enfermería una limpieza de cutis. Sin embargo, la profesional desconocía que al momento de ingresar al Centro, personalmente le propuse al señor dicho procedimiento, a lo cual accedió con mucho agrado, conviniendo que enfermería se encargaría otro día. Debido a que no informamos a todo el equipo de este arreglo, la compañera que recibe al señor, interpreta en su discurso una expresión más de su deterioro.

¿Es más probable que el demente ingrese confuso a enfermería reclamando una limpieza de cutis, o que en otro turno se haya propuesto un procedimiento que no es parte del protocolo? ¿Qué es más loco?

En este ejemplo puede verse cómo discursos/prácticas generadas desde lugares de saber-poder producen a los sujetos que se dice tratar. Señala Vásquez Rocca (2011), más que comunidades científicas, las comunidades de retóricas7 imponen definiciones sobre lo real, entendidas éstas como narrativas exitosas; lo normal como aquello que se

\footnotetext{
${ }^{6}$ Si bien el autor distingue la misma de los "reflejos”, considero que estos también se engloban dentro de "conducta humana” ya que son significados en un marco ético-normativo.

${ }^{7}$ A efectos de este trabajo, recomiendo pensarlas en términos de "regímenes de verdad” foucaultianos.
} 
ajusta a las expectativas de la cultura en un momento y un lugar dados. El diagnóstico de desviación, no explica sino que construye realidad, al mismo tiempo que sostiene acríticamente la noción de un sujeto universal.

En este artículo se sugiere un enfoque a la inversa, ¿̇si en vez de revisar los discursos/prácticas de los locos, revisamos la de los sanos, de los que estamos en posición de generar estas enunciaciones?

\section{La institución como fábrica de locura}

La locura puede entenderse entonces como un producto, creado por y para seres humanos. Si bien me he centrado mayormente en los vendedores/constructores del mismo, es necesario abordar las fábricas en donde se produce.

Tomando los aportes del análisis institucional, se entiende a la institución como un "espacio complejo, hecho de diversos niveles de realidad, en donde confluyen una serie de proyectos e intereses, fundado en prácticas mistificantes” (Payá, 2005: 60), herramientas funcionales a formas sociales producidas desde dinámicas del poder (Manero Brito, 2012) que, lejos de la neutralidad, son influenciadas por las lógicas del Estado (González, 2002).

El paradigma positivista, en el cual se sostiene la hegemonía del conocimiento biológico-mecanicista, influencia determinantemente a las instituciones atravesadas por la lógica asistencial-sanitaria ${ }^{8}$. Desde este paradigma, poco tenemos para problematizar a las instituciones, ya que aparecen como algo dado, generando intervenciones sobre un afuera definido de antemano.

Trascendiendo estas nociones, me centraré en una de las tríadas fundamentales del análisis institucional: instituido/instituyente/institucionalización, colocando la dialéctica mediante la cual se analiza tanto la cristalización como el cambio. La institucionalización entendida como fluctuación entre la equivalencia, lo positivo que logró fijarse, y un proceso que nunca acaba por suprimirse del todo, la negatividad que niega lo instituido (González, 2002). Esta negatividad instituyente aparece en múltiples expresiones: los sucesos informales y las actividades que pueden parecer en principio sin relevancia, pueden constituirse en importantes analizadores para la operación del

8 Entre otros establecimientos: Hospitales generales, Hospitales Psiquiátricos, Policlínicas, Refugios Nocturnos y Centros 24 hs para personas en situación de calle, Centro de Recuperación estatal. 
significante; el pensamiento libre, el sentido como base de creación: “a su manera, resisten el poder impuesto desde los más ínfimos resquicios institucionales en donde la habilidad e imaginación humana prevalecen” (Payá, 2005: 51).

Sin embargo, en las prácticas mistificantes de la institución, la dialéctica de esta tríada queda en el registro de lo oculto, como un cuarto lleno de gas inoloro, se siente más por su densidad ${ }^{9}$, que por comprobaciones acabadas y certeras de los sentidos. La objetividad de los técnicos de las instituciones asistenciales-sanitarias ${ }^{10}$ se basa en la supuesta neutralidad y cientificidad de su saber. Avalados desde este lugar, se generan las intervenciones, se fabrica la locura. Es preciso resaltar que dicho lugar dentro del organigrama de poder, la organización (Payá, 2005), genera responsabilidades no sólo de orden ético a la interna de cada disciplina, sino también legales. Deconstruir por lo tanto los saberes/discursos e instaurar prácticas instituyentes, puede acarrear por ejemplo consecuencias en el orden de la mala praxis.

La sujeción entones es doble, las lógicas del poder constriñen tanto a quienes poseen formal y legalmente el saber, como a los pacientes. Quizás sea sobre esta cuestión en donde hay mayor nivel de horizontalidad institucional, en la pena del desvío.

Buscando dar un sentido al funcionamiento de estas fábricas, tomo el concepto de “carrera moral del paciente mental” de Goffman (2001), como los cambios a nivel del yo ${ }^{11}$, de la imagen propia y de los demás, que se producen en la transición de prepaciente a paciente. Se trata de un mecanismo mediante el cual la persona inicia la carrera gozando de libertades y responsabilidades del mundo civil, y la finaliza despojada prácticamente de todo, reducida al estatus de paciente.

Convertirse en paciente mental implica una mortificación sobre el yo de la persona, que se promueve en primer lugar por el personal de la institución (Goffman, 2001). Bajo una visión biologicista y culpabilizante de la supuesta enfermedad mental,

\footnotetext{
9 Expresión tomada de Alberto cuando algo le parecía sospechoso: "eso es espeso!”

${ }^{10}$ Ejemplo de mi actividad profesional: Equipo psicosocial (trabajadores/as sociales, psicólogas), Equipo Enfermería (doctor/a general, licenciadas y auxiliares en enfermería), Administración (coordinadora, administrativa).

${ }^{11} \mathrm{El}$ autor se refiere en principio al estudio de las Instituciones Totales. Se entiende por estas no tanto el hecho que impliquen las 24 horas del día los 365 días del año, sino en la adhesión total que demandan. Para ser considerada una Institución Total, la misma debe de constituirse en el centro organizador de la vida de la persona (Markwald, 2003). En este caso, el Centro de Recuperación estatal se constituye como tal. Las personas permanecen, salvo excepciones, las 24 hs del día en el Centro, con horarios estipulados (levantarse, comidas, acostarse), y se encuentran controladas no sólo por el equipo técnico (equipo psicosocial y de enfermería), sino por las acompañantes/cuidadoras, las cuales en 3 turnos cubren las 24 horas.
} 
tanto el presente como el pasado son convertidos en profecías auto cumplidas, en las que la persona siempre estuvo enferma.

La mortificación del yo que produce la institución, tiene consecuencias morales, en la forma en que la persona valore y sienta al respecto del mundo que la rodea, el cual es indisociable de su mundo interno. El yo desde un enfoque institucional, en donde su mundo no es tanto suyo, encuentra sus condiciones de existencia en los entramados sociales, culturales e institucionales, desde donde se produce y reproduce:

\begin{abstract}
A semejanza del neófito en muchas de estas instituciones totales, el nuevo paciente se encuentra desposeído de pronto de una cantidad de sus afirmaciones, satisfacciones y defensas ordinarias, y sometido a una sucesión casi exhaustiva de experiencias mortificantes: restricción de libertad de movimiento, vida en común, autoridad difusa de una escala jerárquica y otras similares. Aprende entonces en que pobre medida puede mantenerse la imagen de uno mismo, cuando se quitan repentinamente el conjunto de respaldos que por lo general lo apoyaban (Goffman, 2001: 152)
\end{abstract}

La carrera moral implica por lo tanto, una serie de transformaciones, que poco van teniendo que ver con cualquiera fuera la patología de base que arrojara a la persona a la misma. Las mortificaciones del yo, demandan replanteos en cómo la persona se concibe a sí misma y a los demás (Goffman, 2001).

El paciente mental institucionalizado, entendido desde esta carrera, tendrá que elaborar diversos desdoblajes para de alguna forma sostener su (no tan) propia elaboración del yo. El ascenso en la carrera, lo que Goffman (2001) ejemplifica con el ascenso en el sistema de salas, implica un fino manejo de lo institucional, en donde antes que nada, la persona adscribe a la resignificación de los agentes de la institución.

Vinculando los aportes del análisis institucional, este ascenso en la carrera moral del paciente mental, se desarrolla dentro de un inconsciente institucional: el silencio, el encargo como priorización de unas demandas sobre otras, lo instituido como sistema de roles asumidos, el significado como la cristalización de las prácticas en leyes. La opacidad de la institución por diversos ocultamientos, se expresa en lo que no se expresa, en lo no dicho. La trasnversalidad revela entonces su importancia como forma de elaborar la multiplicidad de sentidos que implica este inconsciente de la sociedad -las instituciones- (Payá, 2005).

Desde la lógica tecnocrática, relacionada con el paradigma hegemónicobiologicista, el saber/ciencia genera la ilusión de que quienes forman parte de la 
organización portan discursos/intervenciones desde lo real, lo comprobado, desde lo dicho. Pero la institución no sólo interviene sobre personas, sino que las conforma como tal. Markwald (2003) señala la paradoja de cómo la misma genera sufrimiento, pero ofrece a su vez los medios para aliviar esta ansiedad. Este espacio transicional winicottiano, como dialéctica entre mundo interno y externo, se coloca como territorio intermedio entre el adentro y el afuera. El acento, más que en la institución en sí misma, está en el uso que se hace de ella:

(...) la institución en su función de apoyatura puede dar lugar a un sujeto creativo, lúdico, donde la institución y el sujeto son vasos comunicantes de una estructura que los excede y que a su vez ellos soportan o, puede dar lugar a un sujeto aprisionado (...) quedando el sujeto a merced de la institución (Markwald, 2003: 4)

El espacio a lo nuevo, a lo creativo, depende de cómo se configure la función de apoyatura. Este espacio transicional impacta sobre las intervenciones de los técnicos, las cuales lejos de desarrollarse desde la neutralidad de lo científico, se relacionan con proyectos que trascienden las finalidades inmediatas y manifiestas produciendo significado y sentido (Manero Brito, 2012). Desde la Gerontología Crítica me pregunto: ¿̇al servicio de qué intervenimos? ¿Qué proyectos reproducimos en nuestra intervención? ¿Desde dónde podemos generar prácticas instituyentes ${ }^{12}$ que rompan con el silencio institucional? ${ }^{13}$

Las fábricas de locura, bajo su proyecto alineado con el paradigma hegemónicopositivista, producen y reproducen prácticas desde una noción biologicista, en donde el distanciamiento de la norma es pensada automáticamente en claves médicasestigmatizantes de salud/enfermedad. Su cualidad hegemónica le permite posicionarse como la única forma posible. Como pregunta Szasz (2001), ¿por qué alejarse de normas psicosociales, éticas o jurídicas deberían de quedar cooptadas desde la lógica médica?

Las prácticas institucionales de quienes formamos parte de la organización, son en gran parte reproducciones acríticas de la opacidad institucional. Es primordial para generar narrativas des-estigmatizantes, poder realizar análisis institucionales transversales, que piensen a las mismas en su multiplicidad de niveles.

En este marco, lenguaje y narración son claves para orientar el proyecto hacia

\footnotetext{
${ }^{12}$ La función utópica del significante niega lo establecido, lo congelado, combate los significados de prácticas cristalizadas, rutinizadas y burocratizadas (Payá, 2005).

13 Ello sin dejar de reconocer, las dinámicas de las instituciones, en donde lo instituyente deviene luego en institucionalización.
} 
una negatividad instituyente. Considerando lo instituido como la visión del cuerpo y de la mente (dominada por el cerebro) en cuanto máquina biológica, tanto la semiología como el método narrativo abren nuevas posibilidades a proyectos des-patologizantes, los cuales pueden generar lugares más empáticos con el sufrimiento humano.

\section{El lenguaje y la denuncia de lo natural}

\section{La potencia de la narración}

Barthes (1978) denuncia la ilusión de lo natural, considerando que la misma adorna una legalidad, una mayoría social. En la medida que la sociedad estructura lo real desde el lenguaje, éste no puede disociarse de lo social, produce pensamiento, se impone al individuo y a su conocimiento del mundo (Beltrán, 1991 en Alonso y Fernández Rodríguez, 2006). Los significados, lejos de una supuesta naturalidad, son atribuidos (significantes) a partir de las explicaciones dominantes, elaborando los signos del sistema cultural (Alonso y Fernández Rodríguez, 2006).

La Ciencia en su búsqueda de verdad, lucha por aprehender esta naturalidad. La explicación última y final del mundo como reflejo invertido del mito ${ }^{14}$, presenta los signos y símbolos de lo social bajo una naturalidad, generando la noción de lo "evidente por sí mismo” (Barthes, 1978).

la escritura engendra escrituras, o, si se prefiere, "literaturas" y a través de estas escrituras o literaturas la sociedad de masas fracciona su realidad en instituciones, prácticas, objetos y hasta en acontecimientos, porque el acontecimiento es ahora siempre escrito (Barthes, 1990: 232 en Alonso y Fernández Rodríguez, 2006: 15)

La institución, lo real, aparece de esta forma mediada por el lenguaje, por la literatura, no puede existir por fuera de este, y lo que allí pasa no le es ajeno. La denuncia de lo natural se declara enemiga de la analogía, de la imagen como fuente de verdad:

El toro se enfurece cuando le ponen el señuelo rojo ante los ojos; los dos rojos, el de la furia y el del señuelo, coinciden: el toro está en plena analogía, es decir, en pleno imaginario. Cuando me resisto a la analogía, de hecho, es al imaginario a lo que opongo resistencia, o sea, a la fusión del signo, a la similitud del significante y el significado, al homeomorfismo de las imágenes, al Espejo, al señuelo cautivador (Barthes, 1978: 53-54)

\footnotetext{
${ }^{14}$ Papel que otrora detentara la Iglesia (Szasz, 2001).
} 
El significante como mediación, huella psíquica, es equiparado y naturalizado al significado, a la imagen mental; un signo fusionado, fundido en la imagen, en el objeto, genera la ilusión de lo evidente por sí mismo (Alonso y Fernández Rodríguez, 2006).

Tomando al signo "locura” como natural, significado y significante (contenido y expresión), aparecen dados, evidentes, sin ninguna injerencia de lo social. En el gran misterio de la etimología de la locura desde la lógica biologicista, se reconoce en diversas patologías o trastornos un funcionamiento en el plano psico-social que se desvía de lo socialmente esperado. Sin embargo, la analogía borra todo vestigio psicosocial, adquiriendo un carácter de naturaleza individual/orgánica.

La analogía de lo loco funciona porque si bien parece apoyarse en la persona, se construye por el contrario desde lo "socialmente esperado". Es este signo el cual prima en la denotación de la locura/normalidad; denotación como verdad del lenguaje, estado verdadero (Barthes, 1978) donde lo real está dado, y lo social parece desvanecerse en lo natural del mito.

Con el foco en la elaboración de proyectos des-patologizantes, el método biográfico narrativo es particularmente relevante a la hora de pensar formas alternativas de intervenir, partiendo de la construcción social de la realidad a través de los relatos disponibles como marcos de posibilidades (de sentir, de pensar, de hacer). Lo real aparece entonces indisociable de los relatos y las narrativas que construyen sentido y significado.

Bruner (2002 en Villar y Serrat, 2015) diferencia dos tipos de pensamiento al respecto. Por un lado, el lógico paradigmático, el cual pretende explicar, describir y predecir fenómenos del mundo, estableciendo relaciones causales y leyes de carácter general. Esta epistemología positivista plantea a lo real como algo dado, externo al investigador, asequible a la racionalidad humana. Por otro lado, el pensamiento narrativo abandona la (supuesta) objetividad, la causalidad, para comprender desde la perspectiva de los protagonistas, el sentido atribuido a la experiencia a través de las historias de vida. De esta forma, el investigador no sólo cuenta, sino también construye la historia a ser contada (Bolívar, 2012).

El análisis narrativo escapa de la búsqueda de categorías cerradas, descarta $l o$ real y lo natural como a priori. La interpretación cobra una nueva relevancia, ya que no accede a algo puro, sino que genera los marcos desde los cuales el entorno, y uno 
mismo, se vuelven asequibles.

(...) su aplicación a textos que no describen hechos sino que reconstruyen mundo/vida en el propio discurso es siempre deficiente, nunca cabe atrapar los matices de la narrativización de una vida bajo una categoría fija (Bolívar, 2012: 89)

El tratamiento categorial silencia la voz de los sujetos al insertarla en categorías creadas artificialmente. Rescatar estas voces no es un acto altruista, ni mucho menos arqueológico. Sin pensarse portador de un saber exclusivo/hegemónico, la voz y la narración más que entidades dadas, implican una reconstrucción por parte de quien escucha. Hablar de una narración, es siempre transcribir (Bolívar, 2012).

La identidad desde la narrativa tiene poco de individual, se construye en la socialización, mediante identificaciones y atribuciones, la imagen de sí mismo indisociable del reconocimiento del otro (Bolívar, 2012). El yo en términos socialmente definidos, a través de relatos autobiográficos en permanente construcción y reconstrucción, transacción recíproca entre lo asumido y lo atribuido:

(... ) el resultado a la vez estable y provisional, individual y colectivo, subjetivo y objetivo, biográfico y estructural, de los diversos procesos de socialización que, conjuntamente, construyen los individuos y definen las instituciones (Dubar, 1991 en Bolívar, 2012:98)

La identidad narrativa más que fijada, en continua elaboración y reelaboración de experiencias, en relatos que generan orden, unidad y sentido (Iacub, 2011). Entre lo discordante y lo concordante, organiza y da coherencia a la vida (Iacub, 2010), continuidad y propósito vinculando pasado, presente y futuro en una narración coherente (Villar y Serrat, 2015). Juego entre el adentro y el afuera, una barrera que parece no ser tal.

Entendiendo a la narración como textos que moldean, controlan o por el contrario abren alternativas (Iacub, 2013), es imprescindible para este artículo considerar los relatos hegemónicos de la vejez y el envejecimiento, ya que ofrecerán el registro de lo posible: figuración (forma en que el sujeto se concibe), refiguración (cuestionamientos a la continuidad y a la integración de la figuración, crisis de significado) y configuración (unidad, integración del caos, volver concordante lo discordante) implican una dialéctica en constante movimiento, en estrecha relación con los avatares propios de las trayectorias vitales (Iacub, 2011). 
Trascendiendo la perspectiva individualista/psicologicista de la gerontología narrativa, que apunta a cómo las personas mayores elaboran relatos de sí mismas, me centro en el plano sociocultural. La vejez como construcción social, y los viejos como las corporificaciones de estas construcciones, encuentran sus condiciones de posibilidad identitaria en los relatos compartidos, en las metanarrativas (Villar y Serrat, 2015).

El discurso no puede ser disociado del contexto de enunciación donde adquiere sentido. El relato como actividad, proceso interactivo relacionado con las condiciones locales del mismo:

\begin{abstract}
Más que la función representativa del lenguaje, lo que se enfatiza es su función performativa, es decir, cómo a partir de las narraciones los hablantes logran determinados efectos. La pregunta clave no es qué nos dice el relato sobre alguien o algo, sino cómo ese relato se elabora y qué se consigue lograr con él (Phoenix, Smith, y Sparkes, 2010 en Villar y Serrat, 2015: 22)
\end{abstract}

El lenguaje no es neutro, y no implica solamente palabras. Esta función performativa remite a los regímenes de verdad y a los discursos/prácticas desarrollados al comienzo de este trabajo (Hüning y Guareschi, 2005). La institución, en la tríada instituido/instituyente/institucionalización, produce narrativas que logran efectos sociales.

El mundo es lo que decimos que es el mundo. ¿Cómo separar lo real de las formas sociales disponibles para hablar de lo real?

Foucault (1990 en Duero y Limón Arce, 2007) al respecto de la racionalidad moderna, analiza las tecnologías para la construcción de subjetividad. Para que el sujeto pueda convertirse en agente, es preciso a la luz del mandato racionalista, que pueda dar cuenta de una narración sobre sí mismo y sus acciones. Coherencia, integración, unidad y propósito como un cuadro coherente (Duero y Limón Arce, 2007). El agente consiste en aquella persona que se ajusta a las narrativas exitosas, de acuerdo a las expectativas culturales definidas en clave de poder-saber. Si el sujeto no logra elaborar un relato que cumpla con estas expectativas universalizantes, queda automáticamente por fuera de la normalidad y la cordura (Duero y Limón Arce, 2007).

Lo que se juzga no es la adaptación o no, sino antes que nada modos de existencia, reflejos de metanarrativas que producen formas validadas de transitar y de sentir. Quedar por fuera de ello, ya no de lo real, sino de las metanarrativas que versan sobre esta supuesta naturaleza, implica verse privado de constituirse en agente. Relegado sistemáticamente a las peores barajas del juego social. 
A continuación presento el análisis de la intervención desarrollada junto a Alberto, usuario del Centro de Recuperación donde realizo mi actividad profesional.

\section{El llanto eterno}

Lo que escuchaba, lo que no podía dejar de escuchar, estuviese donde estuviere, era la sordera de los otros ante su propio lenguaje: él los oía no oírse a sí mismos. Pero, ¿y él? ¿Oía acaso alguna vez su propia sordera? Luchaba por oírse, pero sólo producía con este esfuerzo otra escena sonora, otra ficción (Barthes, 1978:183)

Alberto ingresa al Centro de Recuperación durante el mes de mayo, donde el frio y el congelamiento parece verse reflejado en las prácticas fatigadas, donde el encuentro con el otro usuario parece costar el doble, y el refugio del encierro en la oficina que reza: “equipo técnico”, es vivido como más necesario que nunca.

Me enteré que había un viejo que no paraba de llorar, resistiendo cualquier cuestionario, no recordaba haber estado en situación de calle: la defensa y la paranoia del demente pensaba. Recuerdo pasar por el hall y la situación era siempre la misma: un llanto eterno.

Me resultaba particularmente extraño, la forma angustiosa en la que lloraba, como si se hubiera roto algo adentro. Considerando que el diálogo era imposible, ya que, o no recordaba, o expresamente había información que no quería proporcionar (como el nombre de su hijo o cualquier asociación a su familia), me ofrecí a entrevistarlo. Era nuevo en el trabajo, y con ganas de hacer una demostración.

El resultado fue fútil, información a cuenta gotas, el viejo era inamovible. Su demanda también, ir a Las Piedras en el departamento de Canelones (a $20 \mathrm{~km}$ de distancia del Centro de Recuperación). Sin embargo, por los informes que teníamos, ingresaba al Centro de Recuperación luego de estar en situación de calle en esa ciudad, situación que Alberto negaba ofendido.

Todos los días lloraba, se enojaba, no lograba terminar de comprender su encierro. Un guardia de seguridad en la puerta le negaba la salida, explicándole que tenía que ir a hablar con el equipo técnico. Si bien el Centro de Recuperación no es un centro de reclusión, y las personas pueden abandonarlo voluntariamente, a Alberto se le negaba esta libertad, confinándolo al encierro “por su bien”, por su locura.

Desde la lógica positivista-biologicista la situación no admitía mayores dudas: el 
señor estaba demenciado. En el plano cognitivo había una afectación a nivel de la memoria y de las funciones ejecutivas (planificación, toma de decisiones), sin orientación en tiempo y espacio, no podía dar cuenta de lo que había hecho ayer, ni el mes pasado, ni los últimos 20 años. Un cerebro roto, un cuerpo casi autómata golpeando las puertas del equipo técnico, día tras día, no parecía entender razones, no podía entenderlas. Repetía sistemáticamente que tenía que comer pan dulce, lo cual era entre ridículo e irrisorio.

Empíricamente, parecía corroborarse que con Alberto había una (falacia de) nointervención, no se podía trabajar con esa demencia. Y este era el callejón sin salida del modelo patológico, donde la práctica y lo evidente, cargan en sí mismas el gen de su explicación. Si se pretende descubrir la naturaleza inherente de los fenómenos (Martínez-Guzmán y Montenegro, 2010), ¿qué margen de intervención encontramos con una no-persona?

La falla de memoria de Alberto sin embargo tenía una apariencia selectiva: no olvidaba Las Piedras, no olvidaba el pan dulce. Repetía sistemáticamente: había trabajado toda la vida en la Intendencia de Canelones como concejal, mayormente en la División Tránsito de Las Piedras. Cercano y lejano al mismo tiempo -desde un lugar de subalternidad- de intendentes y figuras relevantes a la interna de la organización y por ende de la ciudad, nos exhortaba constantemente a que preguntemos en la Intendencia quién era él.

Si bien desde el equipo del Centro tratábamos de poner foco en lo estructural que se ponía en juego, el sujeto universal en la supuesta objetividad positivista de lo normal/anormal, se nos filtraban permanentemente en los discursos/prácticas. Alberto continuaba viniendo al equipo para exigir irse a Las Piedras, nosotros continuábamos negándoselo. Sin embargo la preocupación, y nuestra buena voluntad estaban intactas, el problema era epistemológico en primera instancia, encerrados en el callejón sin salida de lo patológico.

En un taller sobre demencia, Robert Pérez y César Valdez ${ }^{15}$, plantean una propuesta que derribaba este posicionamiento. La repetición de la persona con diagnóstico de demencia, más que falla cognitiva, podría interpretarse como significados cristalizados, lo que proponía pasar del tedio de la repetición a los sentidos y significados atribuidos en lo que se repite, sugiriendo una pregunta clave: “¿por qué

15 Docentes del Instituto de Psicología Social, de la Facultad de Psicología, UdelaR. 
eso es relevante para usted?”

Esta propuesta abría una línea de intervención para cuestionar los regímenes de verdad en tanto procesos de subjetivación (Hüning y Guareschi, 2005), discursos/prácticas desde lugares de poder que producen formas de ser, de sentir y de estar en el mundo. Decir que alguien es un demente, también es configurarlo como tal. En este sentido hay dispositivos para personas con diagnóstico de demencia, los cuales se conforman desde la supuesta naturalidad de esta patología, a la vez que la construyen.

No existe algo así como una no-intervención, el diagnóstico más que explicar, da cuerpo y legitimidad a la intervención, que amparada en su supuesta cientificidad, se supone neutra de toda humanidad. Versar sobre el mundo y quienes estamos en él, es crearlo desde atravesamientos políticos, epistemológicos, teóricos, institucionales, sociales y culturales.

La intervención con Alberto sólo pudo ser posible deconstruyendo esta supuesta naturalidad, tanto del viejo como del demente. La Gerontología Crítica, cuestionando los lugares de poder-saber (Bengston, 1997) desde donde se construye realidad, encuentra en este trabajo, su despegue en el método biográfico-narrativo.

Particularmente, era necesario pensar la identidad de Alberto, la cual desde el lugar patológico suponía algo totalmente irrelevante. Desde la narrativa, la identidad se entiende como un conjunto de relatos autobiográficos en constante (re)significación, los cuales generan unidad y propósito (pasado, presente y futuro en un relato coherente) (Villar y Serrat, 2015), dando orden al caos. La identidad como producción y significación permanente de relatos, funciona a modo de mito personal en permanente relación con el intercambio social en función de los espacios transitados. De esta forma, el reconocimiento del otro, la confirmación del afuera (Bolívar, 2012) son componentes centrales de la identidad narrativa.

El pasaje que se propone entonces, es de la unidad-sujeto a las redes discursivas que generan modos de subjetivación; del comportamiento a la internalización de prácticas culturales (Hüning y Guareschi, 2005). De esta forma, el diálogo es un prerequisito del conocimiento, negarlo, es negar a la persona (Martínez-Guzmán y Montenegro, 2010), al silenciar la voz en categorías creadas artificialmente (Bolívar, 2012). Es así que un buen día me senté con Alberto y le pregunté, “¿por qué es importante para vos ir a Las Piedras?” 


\section{La casa de Alberto}

Preguntarle cuál era el significado y el sentido que asociaba con ir a la ciudad de Las Piedras, abría paso a pensarlo por fuera de una categoría rígida que lo anulaba, abriendo espacio a la persona desde la (re)construcción narrativa. Sin embargo, no había un Alberto puro a descubrir, sino más bien un entramado de luchas y fuerzas conflictivas, las cuales era necesario problematizar para orientar la intervención hacia discursos/prácticas despatologizantes, que generaran apertura hacia la persona.

Alberto se nos revelaba desde el lugar en el cual lo construíamos, y por lo tanto, solo podía ser en función de la institución, entendida ésta como productora de subjetividad y espacio transicional (Markwald, 2003), significante desde el cual el individuo es significado (Payá, 2005). Considerando la paradoja institucional planteada por Markwald (2003), en tanto la institución puede constituirse tanto fuente de sufrimiento como de identidad y reconocimiento: ¿qué lugar tenía Alberto en este espacio transicional?

Si bien los espacios de diálogo comenzaban lentamente a generarse, propiciados por una búsqueda narrativa-despatologizante, parecía que hablábamos lenguajes distintos, y en ese ruido, éramos los dos sordos: "Yo tengo una casa en Progreso ${ }^{16}$, tengo que cobrar alquiler, hace meses que no voy”, y nosotros no sabíamos cómo explicarle el sin sentido de esas afirmaciones.

¿Cómo iba a tener un alquiler si estaba en situación de calle en Las Piedras? ¿Un propietario en situación de calle? Más aún, “Progreso... ¿dónde queda?” ¿Cual era la resistencia a buscarlo en el mapa en internet? El freno para indagar no era el tedio, sino el registro de lo imposible en el que Alberto parecía moverse.

En la paradoja institucional se esconde un pacto silencioso, la institución si bien violenta es fuente de identidad. Cuando este pacto se rompe, genera fragilización yoica, una violencia en exceso que niega al sujeto (Markwald, 2003), y esto era precisamente Alberto en el Centro de Recuperación: un sujeto no-reconocido. Sin embargo se resistía a dicha negación, todos los días repetía: “yo tengo una casa en Progreso”. Combatía día tras día, con la misma intensidad, la expropiación de haberse convertido en un paciente mental. En plena carrera moral, Alberto resistía la definición institucional que se hacía de él.

${ }^{16}$ Ciudad ubicada $5 \mathrm{~km}$ al norte de la ciudad de Las Piedras. 
Goffman (2001) señala que el paciente mental sufre una mortificación del yo, en cuanto es forzado a abandonar sus antiguas definiciones sobre él y el mundo que lo rodea. Al ser portador de un yo no-válido, las consecuencias morales de la mortificación se registran en la pérdida de las afirmaciones, definiciones y defensas cotidianas. Desde el personal, se trata de demostrar que la versión institucional, es mucho más consistente que la que tiene el paciente de sí mismo. Alberto, como demente, efectivamente estaba amputado, pero no es la mente la que perdía, sino la amputación moral de una carrera silenciosa, práctica mistificante de la institución.

Al pensar a Alberto, no puedo dejar de sentir la fuerza de la negatividad instituyente, resistiendo la mortificación del yo, luchaba día tras día con la institución que le negaba su propia identidad.

Por cansancio seguramente, y quizás también por un resto de esperanza. A los dos meses le digo que, si efectivamente tenía una casa, me dijera dónde estaba. Rápidamente me dice el nombre de la inmobiliaria, por lo que me dirijo al equipo técnico, busco en internet, discando el número telefónico de la primera página. El diálogo a continuación, sólo puedo (re)crearlo de esta forma:

\footnotetext{
- Buenas, mi nombre es Gastón Pérez, soy trabajador social de un Centro de Recuperación estatal, estamos trabajando con un señor que se llama Alberto, que refiere que...

- Ah! Alberto! ¿Cómo está? Pensamos que le había pasado algo, tiene 6 meses de alquiler para cobrar.
}

Tembloroso de la incredulidad, y con un dejo de satisfacción propia por haberme de alguna forma animado a llamar, le transmito al resto del equipo: “Alberto es propietario, tiene 6 meses de alquiler para cobrar”. Esta afirmación, resquebrajaba los pocos esquemas positivistas que se seguían filtrando, implicaba un golpe más a la categoría de Alberto como demente/loco, le daba un nuevo sentido a su llanto, al pan dulce, al sufrimiento. Y es que el supuesto alejamiento de la norma, fuera de la noción patológica, nos confrontaba a nosotros en cuanto equipo, ¿técnicos?, ¿personas?, representantes de la violencia institucional.

El pensamiento del viejo en clave de adaptación/no adaptación, propio de las teorías del declive (Díaz-Tendero, 2011) revelaba su agotamiento, ¿qué lugar hay para el sufrimiento de Alberto entendido como un cuerpo y mente en declive?

El valle de lágrimas, se convierte en un valle de enfermedades cuando la Ciencia 
reemplaza el papel de la Iglesia (Szasz, 2001), la des-adaptación como definición instantánea de locura. Sin embargo, lo instituyente en cuanto negación, tiene un poco de loco. Y la repetición de Alberto era tan loca como sana: ¿es loco pelear por la identidad reconocida como propia?

La patologización esconde, no sólo a la persona detrás del diagnóstico, sino también a nosotros técnicos/profesionales en tanto seres institucionales. El diagnóstico objetivista calma, da seguridad, generando una (pseudo) auto-exclusión del juego de enunciación-poder-construcción. No permite ver que lo que está en juego es la propia implicación. Acercarnos a la persona implica una postura que transite de la descripción a la comprensión, de la patologización a los sentidos y significados en juego, de la categorización artificial al cuestionamiento: ¿cualquier forma de sufrimiento es una enfermedad? (Szasz, 1994).

\section{Unas vacaciones por Las Piedras}

Estar con Alberto en la ciudad de Las Piedras, fue lo más cercano a un paseo en el tiempo que viví. Incluso la experiencia, la revivo en blanco y negro, como esas fotos viejas que me mostraban de niño. Los personajes, si bien actuales, parecían fantasmas encarnando relatos congelados del pasado. Como una especie de "The Truman Show ${ }^{17, ",}$ en donde él era tanto el principal actor como el canal de televisión, víctima y victimario en una fantasía puesta en juego; me pregunto sin embargo, en qué medida el otro no es siempre una proyección de nosotros mismos, y por ende una fantasía puesta en juego. $\mathrm{Y}$ en ésta, ¿cuál era mi show?

La intervención y la apertura desde una crítica despatologizante, la institución como espacio transicional, el discurso/práctica desde la Gerontología Crítica, comenzaban a entrar en tensión con la opacidad de la institución, las reglas de lo no dicho, los no se puede o no se sabe bien por qué no debe hacerse.

Acompañar a Alberto a cobrar su jubilación en ANDA (asociación civil mediante la cual percibía sus ingresos) sucursal Montevideo, dejaba gusto a poco. No bastaba con ir a tomar un café luego, explicarle que no se veía adecuado que me invite, así que cuando insistía mucho, accedía a colaborar con la propina. No bastaba con ir a la Avenida 18 de Julio a comprar calzado. Él tenía su ANDA en Las Piedras Canelones, su

${ }^{17}$ Película de género comedia dramática y ciencia ficción, dirigida por Peter Weir y protagonizada por Jim Carrey. 
zapatero en Progreso, a media cuadra de la inmobiliaria, de la cual seguía sin cobrar los meses de alquiler.

El propio proceso de intervención generó una tensión tal -sólo así podía tomarse esta decisión- que consultando con mi equipo y la coordinación planteo: “¿y si acompaño a Alberto a Progreso a cobrar el alquiler y después a Las Piedras?”. Las ventajas eran muchas: seguíamos sin saber nada de su familia, por otro lado, desde una visión pragmaticista, ello evitaría, esperábamos, que bajara su demanda constante en el equipo técnico.

Dos papeles como estandartes llevaba en mi mochila camino a Progreso con Alberto. El primero, una hoja que firmamos los dos, en donde se registraba que salíamos a Las Piedras y que en la tarde nos comprometíamos a regresar al Centro de Recuperación. La otra, a modo de último recurso, era un egreso voluntario. En caso que quisiera quedarse, le exigiría firmar el documento certificando que dejaba el Centro de Recuperación por voluntad propia sin alta del equipo.

En un momento, trasladándonos en ómnibus de Progreso a Las Piedras Alberto me dice: “yo no sé cómo vas a volver vos”. La pesadilla temida. Regresar al Centro y explicar a la supervisión que perdí al viejo ¿Y que lo perdí por qué? ¿Por una salida médica? ¿En un trámite institucionalizado en el Banco de Previsión Social? No, en una suerte de acompañamiento terapéutico. Sin embargo, la tensión de este momento se disipa al rato, ya que apelo a que había dado su palabra de regresar al Centro. Salvado por los viejos valores.

La ilusión de la persona con diagnóstico de demencia como impredecible, si bien rondaba en mi cabeza, conforme sumábamos salidas a Las Piedras una vez por mes, comenzaba a desvanecerse. Me sentía un adicto al relato, todo lo que Alberto me había contado lo quería ver: La División de Tránsito de la Intendencia de Canelones, el Bar El Patriota, ANDA Las Piedras, la zapatería, el supermercado Covadonga ${ }^{18}$, y la inmobiliaria de Progreso. Como una fábula cobrando vida, un mundo esencialmente inexistente desde la lógica positivista, como el que teje el demente, se levantaba encarnando personas y cosas.

Bonaparte, frente al segundo suicido de un granadero por (des)amor en el mismo mes, dispone en la orden del día que el soldado “debe vencer el dolor y la melancolía de

${ }^{18}$ El mayor supermercado de la ciudad de Progreso. 
las pasiones; que hay tanto coraje verdadero en sufrir con constancia las pesadumbres del alma como en afrontar la metralla de una batería...” (Barthes, 1978: 102).

Al respecto señala el autor:

\begin{abstract}
Estos granaderos enamorados, melancólicos, ¿de qué lenguaje sacaban su pasión (poco conforme a la imagen de su clase y su oficio)? ¿Qué libros habían leído o qué historia habían oído? La perspicacia de Bonaparte está en haber asimilado el amor a una batalla, y no, banalmente, porque en ellos se enfrenten dos contrincantes, sino porque, hiriente como la metralla, la ráfaga amorosa provoca entorpecimiento y miedo: crisis, revulsión del cuerpo, locura: el que está enamorado a la manera romántica conoce la experiencia de la locura. Ahora bien, a este tipo de loco hoy día no se le aplica ninguna palabra moderna, y es por ello, a fin de cuentas, por lo que se siente loco: no tiene lenguaje que robar - a no ser que sea muy antiguo (Barthes, 1978: 102)
\end{abstract}

Algo así nos pasaba con Alberto en la institución, parecía que no teníamos “lenguaje que robar”. Las significaciones, los signos que intercambiábamos, parecían más que negarse, ni siquiera reconocerse. La sordera de los otros frente al propio lenguaje, reconocer la sordera propia, luchar por oírse en medio de la ficción. La comunicación entonces solo fue posible cuando empezamos a tejer significaciones: el pan dulce era mucho más que un pan dulce, eran las lógicas de poder, de la salud y la enfermedad, el cuerpo de antaño sano/gordo, ahora nervioso/flaco como recuerdo permanente de una pérdida material, pero sobre todo simbólica.

Alberto sólo podía ser Alberto en la ciudad de Las Piedras. Como un exiliado, lo que lo separaba al Centro de Recuperación, no era la distancia sino lo simbólico. El taxi hasta Las Piedras operaba a modo de alquimia, no éramos los mismos una vez fuera.

El inmigrante indocumentado, daba paso al ciudadano, de pre-paciente a paciente, rápidamente recorría el camino inverso. El lenguaje cobraba nuevas dimensiones, y sin embargo nuestra relación allá no era algo completamente nuevo. Más que ser Alberto la voz de autoridad, parecíamos quedar sí en planos más horizontales. Al momento de manejar el dinero por ejemplo, sobre todo en la inmobiliaria, me pedía que lo ayudara, y este no-poder no era algo angustioso, sino al contrario, orgulloso de tener al lado a alguien complementario. Y es que allí, yo era un "buen amigo" como él me presentaba.

En una de las salidas a Las Piedras, a mitad de camino reparo que no habíamos agarrado la cédula de identidad. Le pido al taxista que frene, volvemos al Prado. Alberto se niega rotundamente, iríamos sin cédula. Accedo con incredulidad, un tanto enojado en mi nerviosismo: “si no llegás a cobrar volvemos el mes que viene”. La amenaza 
parece pasarle por el costado: “a mí me conoce todo el mundo allá”.

Llegamos a ANDA y le digo a Alberto que lo espero en el hall, no sentía que tenía que hacerme cargo de la ridiculez de cobrar sin cédula. A los pocos minutos regresa con el dinero, y mi capacidad de asombro nuevamente en jaque: “¿cómo hiciste?”. Su respuesta tan simple como compleja: “te dije que acá me conoce todo el mundo”. Ni los funcionarios, ni la ciudad, ni el departamento: el mundo. Alberto pocas veces usaba la palabra ciudad, Las Piedras era una categoría en sí misma, dada, y él ahí también.

Amenazar, engañar, acompañar, entender, enojarse, reírse, implicarse. Y es que hace un tiempo pienso sobre el título de este apartado, las “vacaciones en Las Piedras”, ¿eran de Alberto o mías?

Acevedo (2002) señala que la resistencia a la implicación, más que a ésta en sí misma, es a abandonar la pureza de los juicios y actos, un rechazo a aceptar los factores psico-sociales que condicionan tanto el acercamiento como lo que se calla (González, 2002), determinando más allá de lo que se pretende controlar. Implica reconocerse objetivado por aquello que se pretende objetivar (Acevedo, 2002).

La implicación, si bien no puede suprimirse, ya que sería de alguna forma suprimir a la propia persona en juego, es necesario analizarla: qué se juega en el espacio, en el vínculo. Supone no perder de vista las implicaciones tanto sociales como libidinales (Acevedo, 2002), la estructura psicológica, el lugar de la institución donde es/se colocado/coloca, nuestra identidad en su expresión más singular. Por otro lado, estar sobre-implicado, es condenarse a la inercia de poderes que se desconoce. Con ello, no pretendo caer en un positivismo de la mente y las instituciones, construidas como entidades dadas, exteriores y objetivas.

Pensar la implicación como horizonte no pretende -no debería pretender considero- constituirse en la explicación última y verdadera de todo lo que está en juego. Señala Barthes (1978: 183): “¿Lo propio de lo real; no será ser indomable? Y lo propio del sistema, ¿¿no será quererlo dominar?”

\section{La fábrica narrativa}

Las Piedras aparecían frente a mí como el producto, o la materialización, de mi propia significación sobre la narrativa de Alberto. No conocía previamente la ciudad, ni 
a ninguna persona de allí, incluso no sabía ubicarla en el mapa, un vago sentido adjudicado a través de referencias difusas: "una de las tantas ciudades del departamento de Canelones".

Decir Alberto era decir Las Piedras. Un enclave de identidad, en donde él sólo podía ser en función de la referencia territorial-simbólica. La posición socio-económica y el estatus gozado/narrado, cobraba vida en el tránsito por estos espacios. Es así que la narrativa quedaba cristalizada, dependía de la revelación física, real, de estos lugares, como el bar en donde "todos me conocen".

Desde una lógica positivista/organicista podemos decir que no estaba orientado en la realidad ¿Cómo negarlo? Alberto no tenía redes vinculares de contención como poníamos en los informes del trabajo, efectivamente, la fantasía de época y la ciudad amigable, no resistía, se quebraba cuando se la desafiaba, Alberto terminaba en situación de calle.

Desde que ingresa al Centro de Recuperación, termina dos veces en calle en Las Piedras. Al mes de haber ingresado, se coordina su egreso a un hogar de larga estadía (casa de salud), del que al mes se retira. Vuelta a Las Piedras, vuelta al Centro. En otra oportunidad, frente a su insistencia de ir a dicha ciudad, firma egreso voluntario. Al otro día, nuevamente estaba en el Centro.

Había una sensación de que estaba en un $l o o p^{19}$, girando en círculos. Y en estos círculos, el tiempo se borraba porque había perdido sentido. ¿Qué importaba el año o el mes? Al revés, estas nociones entorpecían porque implicaban historizar, lo cual lo sacaba del loop.

Entendiendo a la identidad narrativa en función de los espacios transitados (Bolívar, 2012), Alberto parecía dominar esto a la perfección, así se paseaba por ANDA, por el bar, recreando su loop. Al borrarse el tiempo, los personajes quedaban congelados también con sus atributos de antaño: el amable, el embaucador, el lugar donde le servían cualquier comida que pidiera, el gerente de ANDA que le gusta tomar vino, etc.

Pensando su elaboración narrativa, la representación que hacía Alberto de sí mismo, su figuración parecía haber quedado trunca, interpelada por nuevos contextos que no pudieron ser integrados. Refiguración como quiebre de sentido (Iacub, 2010), cierre narrativo en la dificultad para adaptarse a cambios y desafíos (Freeman, 2011 en Villar y Serrat, 2015), ruptura biográfica-narrativa por un nuevos contextos de

19 Del inglés: estructura o proceso circular, que termina donde comienza y así sucesivamente. 
significación que demandan reelaboración identitaria (Iacub, 2011).

Alberto aparecía entonces interpelado por los cambios vitales, y como defensa tenía la bandera del loop deslumbrante de Las Piedras. Desde una óptica narrativa, aparecían duelos no elaborados que de alguna forma cortaban la narrativa, congelando todo lo que había en ella. En palabras de Goldfarb (Berriel y Pérez, 2007) un sujeto históricamente constituido que para salvarse se pierde, empujado a un olvido traumático al no poner nuevos objetos en los lugares de pérdida ${ }^{20}$. Previo a la muerte biológica, una muerte histórica y social.

En este caso dos pérdidas como agujeros negros de sentido: jubilación y viudez. Con respecto a la primera señala Iacub (2010: 301):

\begin{abstract}
“(...) la jubilación aparece como una categoría a partir de la cual el sujeto se sitúa en relación a los otros desde un cierto espacio de valoración y poder, y en donde la pérdida de aquel lugar lo deja sin ese bien que da forma a su sí mismo o ante el interrogante del 'quien es'. Esta refiguración que deja al sujeto desenclavado de las referencias habitual produce efectos en la temporalidad del relato"
\end{abstract}

Decía Alberto: “fui concejal en Las Piedras”; decía Alberto entre la angustia y la rabia, pienso, del dolor y la sorpresa al descubrir lo frágil y volátil en que puede llegar a convertirse lo simbólico. Esta figuración aparecía cuestionada por un nuevo contexto, donde las lógicas del poder, el estatus en función de los espacios transitados, se desvanecían en un quiebre que no admitía re-elaboración alguna. El loop no permitía integrar la experiencia, no ofrecía cohesión, ni sentido, lo cual implicaría ya una configuración como integración del caos (Iacub, 2010).

La jubilación y la viudez en función de las metanarrativas del envejecimiento, guiones culturales que generan los marcos de posibilidad, implican pensar al relato como actividad en sus efectos performativos, en cuanto construye realidad. La narración como una forma de acción social (Villar y Serrat, 2015) produce performances repetidas que generan la ilusión de un estado natural (Martínez-Guzmán y Montenegro, 2010).

La performatividad nos abre la línea de interpretación, en donde lo real no está dado, sino que se construye en el proceso interactivo de contar relatos. Señala Kenneth Gergen (2006), a medida que aumenta el lenguaje del yo, se amplía el repertorio de las relaciones humanas, expandir el vocabulario de uno, es expandir las posibilidades del otro. Por el contrario los límites del lenguaje del yo, implican límites en el mundo de la

20 (Goldfarb, 2004) 
persona:

"[Los conceptos relativos al yo] operan en el individuo y la sociedad como realidades funcionales que contribuyen a fijar los límites de esa misma naturaleza humana de la que, presuntamente, deberían ser un modelo” (David Bohm en Gergen, 2006: 23).

En el caso de Alberto, el lenguaje del yo era doblemente limitado, tanto por su elaboración narrativa, como por la institución, su mundo se reducía doblemente. El cierre de la narrativa chocaba de lleno con otro cierre, el de la opacidad de la institución, lo no dicho, las reglas silenciadas, los códigos incuestionados y la rigidez.

Sin embargo, la apertura desde la narrativa como forma de apertura humana, comenzaba a producir cambios en una narrativa congelada. Alberto, que hasta el momento me nombraba como Pablo (personaje familiar lejano en su narrativa), comenzaba a llamarme por mi nombre. De alguna forma, me unía a su narrativa, integrando la experiencia y generando sentido. Las Piedras seguía siendo Las Piedras, pero Alberto comenzaba a ser un poco Alberto en el Centro de Recuperación también. La configuración como mediación entre la concordancia y la discordancia (Iacub, 2010), comenzaba a tejer nuevamente un orden temporal, vislumbrando otra forma posible de ser en la institución.

Esta elaboración narrativa considero, fue uno de los mayores aprendizajes de la intervención. En medio de este mar de tensiones, hubo una brecha instituyente, una oportunidad para romper el silencio, dando margen a la creatividad y lo novedoso.

De todas formas, el soporte de identidad era Las Piedras. La poca familia que pudimos localizar no deseaba ningún tipo de acercamiento con Alberto, salvo por una hermana en una casa de salud, con diagnóstico de declinación funcional y demencia, revelaba el abandono y sufrimiento -¿propios?, ¿sociales?, ¿culturales?- que pueden arrojar a una persona a la muerte simbólica. Luego de ver a su hermana, Alberto queda movilizado y la ida mensual a Las Piedras, parecía quedar mucho más corta que antes. El tironeo era grande y la contradicción estructural. Tenía que dejar el Centro.

En septiembre del 2017 acompaño a Alberto en su egreso a un hogar de larga estadía en Las Piedras, el cual fue a conocer previamente con una integrante del equipo. Tanto a él como a nuestro equipo, nos pareció una buena opción, con margen de movilidad y cuidado. 
A los dos o tres meses me avisan de su delicado estado de salud, y al poco tiempo de su fallecimiento. Su muerte aún resuena en el Centro de Recuperación: “¿te acordás de Alberto?”, “cómo lloraba”, “el pan dulce de Alberto!”, “cuando te decía: ¿¡iah y por qué quiere saber eso!?”, “cuando fuimos al Shopping de Las Piedras y se compró un saco carísimo”. Su muerte aún resuena en quienes ponemos mucho más que el cuerpo en el trabajo con personas.

\section{Consideraciones finales}

¿Fue así? ¿Realmente pasó o es todo parte de un invento? ¿Acaso los hechos reales fueron forzados para cuadrar en un análisis académico? ¿Se violenta la historia en la búsqueda estética de la narración? ¿Acaso importa? La significación de lo que fue esta intervención, solo puede ser concebida en términos de reinterpretación subjetiva, ¿hay una esencia a transmitir?

Traer a la palabra, al relato, implica una transcripción. Como señala Bolívar (2012), el investigador no ofrece la historia en estado puro, sino que la construye en el acto mismo de la narración.

Comenté al comienzo, este es un trabajo que se sabe y se enorgullece de ser subjetivo, empapado de sentimientos, de falta de neutralidad. Intenta ser un aporte para pensar los discursos/prácticas en contextos institucionales, problematizando las lógicas de poder que se reproducen en forma acrítica, recortando los márgenes de lo posible.

Gergen (2006) expresa que nos encontramos en un momento histórico en donde el vocabulario de las “flaquezas" humanas, aumenta bajo la producción de la cientificación de la conducta en la era moderna. El "arte del protocolo y la etiqueta” traspolado al yo, implica un manejo cuasi profesional de la salud, o más bien, de la no enfermedad mental. La creciente terminología impacta sobre el propio mundo que dice explicar, generando una “espiral cíclica de debilitamiento personal” (Gergen, 2006: 36).

Esta patologización propia de la racionalidad moderna, en su intento por ordenar la suciedad y clasificar la contingencia (Hüning y Guareschi, 2005), genera que quien se aleje de la norma -el loco, el viejo (con su profecía auto cumplida de demencia)- sea culpable hasta que se demuestre lo contrario. Las metanarrativas como marcos de posibilidades, los alejan de constituirse en agentes, al no contar con un tipo de relato que se adapte a la exigencia totalitaria del sujeto universal. El no poder elaborar estos 
relatos, implica quedar por fuera de la normalidad y la cordura (Duero y Limón Arce, 2007).

Sin embargo, ¿es el sujeto el que no puede, o es la configuración social? ¿Es la persona la que no habla, o la institución la que no oye?

La locura es lo que hacemos de la locura; los discursos y las instituciones crean lo que luego pasan a registrarse como hechos naturales: todos sabemos, al menos creemos saber, cuando tenemos a un loco en frente. Pero si por un momento pensamos en lo loco en cómo configuramos lo diferente, y fantaseamos con narrativas alternativas, podemos vislumbrar una persona que se asoma por detrás de la categoría congelada. Gran parte de la taxonomía se pierde y quizás sonaremos más modestos frente a los y las colegas, porque estaremos hablando de personas más que de entidades silenciosas que operan desde la clandestinidad de los cerebros.

La propuesta y la invitación es un poco a desarmarse, a rearmarse y en última instancia, a reconocerse armado. El fanatismo de la empiria es un mito más, quizás para ver no precisemos ojos. 


\section{Referencias bibliográficas}

ACEVEDO, María J. La implicación. Luces y sombras del concepto lourauniano. Universidad de Buenos Aires: Facultad de Ciencias Sociales, 2002.

ALONSO, Luis E.; FERNÁNDEZ RODRÍGUEZ, Carlos J. Roland Barthes y el Análisis del Discurso. In.: Empíria. Revista de Metodología de las Ciencias Sociales, núm. 12, pp. 11-35, Madrid, España, 2006.

AMERICAN PSYCHIATRIC ASSOCIATION. Diagnostic and statistical manual of mental disorders (4th ed.). Washington DC.,1994.

Washington, DC., 2013.

Diagnostic and statistical manual of mental disorders (5th ed.).

BARTHES, Roland. Roland Barthes por Roland Barthes. Barcelona: Ed. Kairos, 1978.

BENGSTON, Vern L.; BURGESS, Elisabeth O.; PARROTT, Tonya M. Theory, Explanation, and a Third Generation of Theoretical Development. In.: Social Gerontology. Journal of Gerontology: Social Sciences, vol. 52B, $\mathrm{N}^{\circ}$ 2, 1997. Recuperado de: http://gero.usc.edu/asa_files/shannon/BengstonTheory.pdf

BERRIEL, Fernando; PÉREZ, Robert. Alzheimer y Psicoterapia: clínica $e$ investigación. Montevideo: Psicolibros, 2007.

BOLÍVAR, Antonio. Metodología de la investigación biográfico-narrativa: Recogida y análisis de datos. In.: Dimensões epistemológicas e metodológicas da pesquisa (auto)

biográfica, pp. 79-109. Universidad de Granada, España, 2012. Recuperado de:

https://www.researchgate.net/publication/282868267_Metodologia_de_la_investigacion _biografico-narrativa_Recogida_y_analisis_de_datos?enrichId=rgreq-

6e5bcf0c7ae2f997420f9a4186af1709-

XXX\&enrichSource=Y292ZXJQYWdlOzI4Mjg2ODI2NztBUzoyODUxMzM4ODcyO TU0ODlAMTQ0NDk5MjYyNDQ4Mw\%3D\%3D\&el=1_x_2\&_esc=publicationCoverP df

DÍAZ-TENDERO, Aida. Estudios de Población y enfoques de Gerontología Social. In.: Papeles de población, 17(70), pp. 49-79, México, 2011.

DUERO, Dante G..; LIMÓN ARCE, Gilberto. Relato autobiográfico e identidad personal: un modelo de análisis narrativo. In.: Revista de Antropología Iberoamericana, mayo-agosto, año/vol. 2, número 002, pp. 232-275, Madrid, España, 2007.

FOUCAULT, Michel. El juego de Michel Foucault. In.: Saber y Verdad, pp. 127-162, Madrid: Ediciones de la Piqueta, 1984.

GERGEN, Kenneth. El yo saturado. Dilemas de identidad en el mundo contemporáneo. Barcelona, España: Ed. Paidós, 2006. 
GOFFMAN, Erving. Internados. Ensayos sobre la situación social de los enfermos mentales. Buenos Aires, Argentina: Ed. Amorrortu, 2001.

GOLDFARB, Dellia C. Demências. SP, Brasil: Casa do Psicologo, 2004.

GONZÁLEZ, Fernando M. Análisis Institucional y Socioanálisis. In.: Revista Tramas 18-19, pp. 51- 72, UAM-X México, 2002.

HÜNING, Simone M.; GUARESCHI, Neuza M. F. Problematizações das práticas psi: articulações com o pensamento foucaultiano. In.: Athenea Digital, núm 8, pp. 95-108, Pontifícia Universidade Católica do Rio Grande do Sul, Brasil, 2005.

IACUB, Ricardo. El Envejecimiento desde la identidad narrativa. In.: VERTEX Rev. Arg. de Psiquiat. 2010, Vol. XXI, pp. 298- 305, 2010.

2011.

Identidad y Envejecimiento. Buenos Aires, Argentina: Paidós, Nuevas reflexiones sobre la Posgerontología. In.: Revista Kairós Gerontología, 16(4), pp. 295-311, 2013.

MANERO BRITO, Roberto. El devenir del socioanálisis. In.: Revista Tramas 37, pp. 215- 240. UAM-X México, 2012.

MARKWALD, Diana. Sujeto, grupo,institución. ¿Una relación posible?. In.: Campo Grupal, N. ${ }^{\circ}$ 47, pp. 4-6, 2003.

MARTÍNEZ-GUZMAN, Antar.; MONTENEGRO, Marisela. Narrativas en torno al trastorno de identidad sexual. De la multiplicidad transgénero a la producción de transconocimientos. In.: Prisma Social, núm. 4, pp. 1-44, Las Matas, España, 2010.

PAYÁ, Víctor A. Teoría social y socioanálisis. In.: Institución, imaginario y socioanálisis, pp 47-86, México, 2005.

SZASZ, Thomas. El mito de la enfermedad mental. Buenos Aires: Amorrortu editores, 1994.

editores, 2001.

Ideología y enfermedad mental. Buenos Aires: Amorrortu

VÁSQUEZ ROCCA, Adolfo Antipsiquiatría. Deconstrucción del concepto de enfermedad mental y crítica de la 'razón psiquiátrica'. In.: Nómadas. Critical Journal of Social and Juridical Sciences, 31(3), s/p., 2011

VILLAR, Feliciano; SERRAT, Rodrigo. El envejecimiento como relato: Una invitación a la gerontología narrativa. In.: Revista Kairós Gerontologia,18 (2), pp. 09-29. São Paulo, Brasil, 2015. 